\title{
Integração da vigilância em saúde na zona da mata mineira: desafios e potencialidades
}

Cíntia Pereira Donateli, Ariadne Barbosa do Nascimento Einloft, Patrícia Silva Avelar, Tania Segura Quesada, Glauce Dias da Costa, Rosangela Minardi Mitre Cotta

\section{Resumo}

A integração entre as Vigilâncias em Saúde visa à reorganização dos serviços para atender às necessidades locais, abarcando prevenção e controle de doenças e promoção da saúde. A valorização da Vigilância em Saúde e sua atuação integrada com a Atenção Primária podem possibilitar a construção de uma rede forte e eficiente de vigilância, permitindo que os agravos à saúde sejam monitorizados de forma eficiente e auxiliem em situações de emergência e reermergência das doenças. Assim, essa proposta deve ser encorajada, visto que ações de Vigilância em Saúde precisam de suporte de diversos setores e órgãos para o seu pleno desenvolvimento. $\mathrm{O}$ objetivo do estudo foi identificar os desafios e as potencialidades do processo de integração municipal entre as Vigilâncias Sanitária, Epidemiológica e Ambiental da Zona da Mata Mineira. Trata-se de um estudo avaliativo de abordagem quanti-qualitativa, cujo universo da pesquisa foi composto pelos sete municípios-polo de saúde da Zona da Mata mineira: Cataguases, Juiz de Fora, Manhuaçu, Muriaé, Ponte Nova, Viçosa e Ubá. A coleta de dados ocorreu no primeiro semestre de 2016, por meio de entrevista aos coordenadores locais das Vigilâncias Epidemiológica, Ambiental e Sanitária. O questionário elaborado com base na tríade Estrutura/Processo/Resultado de Donabedian, continha questionamentos referentes à integração das ações e às parcerias com outros setores e órgãos. O presente estudo foi aprovado pelo Comitê de Ética em Pesquisa com Seres Humanos da Universidade Federal de Viçosa, com parecer $n^{\circ} 1447272$. Dentre os principais desafios observados, tem-se que a maioria dos municípios não possui estruturação organizacional ideal das vigilâncias, gerando sobrecarga de algumas áreas. Apenas uma cidade conta com a sala da situação de saúde e uma delas não possui o cargo de coordenador geral da Vigilância em Saúde, implicando falta de interlocução entre as vigilâncias. Foram observadas falhas nas ações de promoção da saúde, pois são realizadas unicamente pela Atenção Primária. Ademais, a avaliação externa e monitoramento das ações são feitos segundo as metas quantitativas, ignorando a qualidade do serviço prestado. As principais queixas dos entrevistados referem-se às limitações de recursos materiais, inviabilizando, principalmente, as atividades de campo; ao mau funcionamento dos sistemas de informação associado à má qualidade da internet, que geram problemas técnicos de sobrecarga no servidor; e ao quantitativo de recursos humanos, que dizem ser insuficiente. Como potencialidades, identificou-se a integração das ações com as equipes de Estratégia de Saúde da Família; o uso do documento-base para execução das ações como instrumento condutor; a existência de canais de comunicação que facilitam a troca de informações entre as vigilâncias e melhoram a notificação dos dados, bem como de profissionais em cargo de chefia, em sua maioria, capacitados, experientes e efetivos. A descentralização associada à integração das ações de Vigilância em Saúde encontra-se em processo incipiente de implementação para todos os municípios. Em decorrência do potencial de impacto positivo no perfil de morbimortalidade locais, se faz necessário o fortalecimento do monitoramento qualitativo das ações e a melhoria a capacidade de análise dos dados epidemiológicos gerados, bem como seja promovida a educação permanente dos profissionais.

Descritores: Vigilância em Saúde; Atenção Primária à Saúde; SUS. 